\title{
OPPORTUNITIES TO EXPAND THE OFFERED ADMINISTRATIVE SERVICES FROM THE CAREER CENTERS
}

\author{
R. Kirilov* \\ University of National and World Economy, Sofia, Bulgaria
}

\begin{abstract}
Purpose. An important prerequisite for the successful completion of the graduating students is the good functioning of the career center of each higher school. Given the current tendencies of digitization of the services provided, it is necessary to seek opportunities for their expansion. The main objective of the present study is to build on the experience gained and the practices applied in the higher education institutions providing career services to students to seek opportunities to improve this process. Methods. In order to achieve this goal, various methods are used in the publication, such as the method of empirical analysis and synthesis, the analysis of current regulations and studies among students. Results. The results obtained are in the direction of building and developing modern communication channels and modern digital electronic administrative services for the students. Conclusions. The conclusions outline the main challenges facing the higher education career centers and the opportunities for expanding the provided administrative services for the students.
\end{abstract}

Key words: administrative services, e-services, information technology, career centers

\section{INTRODUCTION}

Career development of students is an important and responsible task. In order to achieve it in recent years, higher education institutions have invested considerable resources. It was primarily aimed at improving the universitybusiness relationship, developing and modernizing career centers, and more. In this context, digitization processes have revealed new opportunities for developing the services offered by career centers. The opportunities for employers' presence and their suggestions in higher education institutions, as well as opportunities for students, have greatly improved. The latter are mainly related to the demand for positions for internship, work, various trainings, acquired competencies, etc. This study is also directed in this direction. It aims, based on empirical experience and contemporary theoretical formulations, to propose approaches to expand the services offered by career centers.

\footnotetext{
*Correspondence to: Rosen Kirilov, University of National and World Economy, Sofia 1700, tel. +35928195 693,e-mail: rkirilov@unwe.bg
}

\section{CHALLENGES TO CAREER DEVELOPMENT OF STUDENTS}

The challenges faced by the career development of students are mainly related to the emerging changes in the labor market. These dynamic economic, social and societal changes require the implementation of new policies by higher education career centers. The latter should become an active participant in expanding the university-business relationship. Offering new and more digitized services by career centers will improve the realization of graduating students. This can also become one of the leading motives for choosing a given higher education institution from candidates. In the scientific literature, there are several definitions of public services as well as administrative services. In the present study, we will stick to Kirilova's definitions that public electronic services have two main features: they have the characteristics of administrative electronic services; compliance with the defined request and response rules [1]. By analyzing good examples of such services, the Interuniversity Center for Career Development (ICCD) of the University of National and World Economy [2] must be mentioned. It is the oldest career center in high schools. Over the last few years several new measures and activities have 
been implemented to modernize its work. They give a new look to the relationship, both with students and with employers. Based on the experience gained in the ICCD, the following main challenges for the career development of students can be identified (Figure 1):

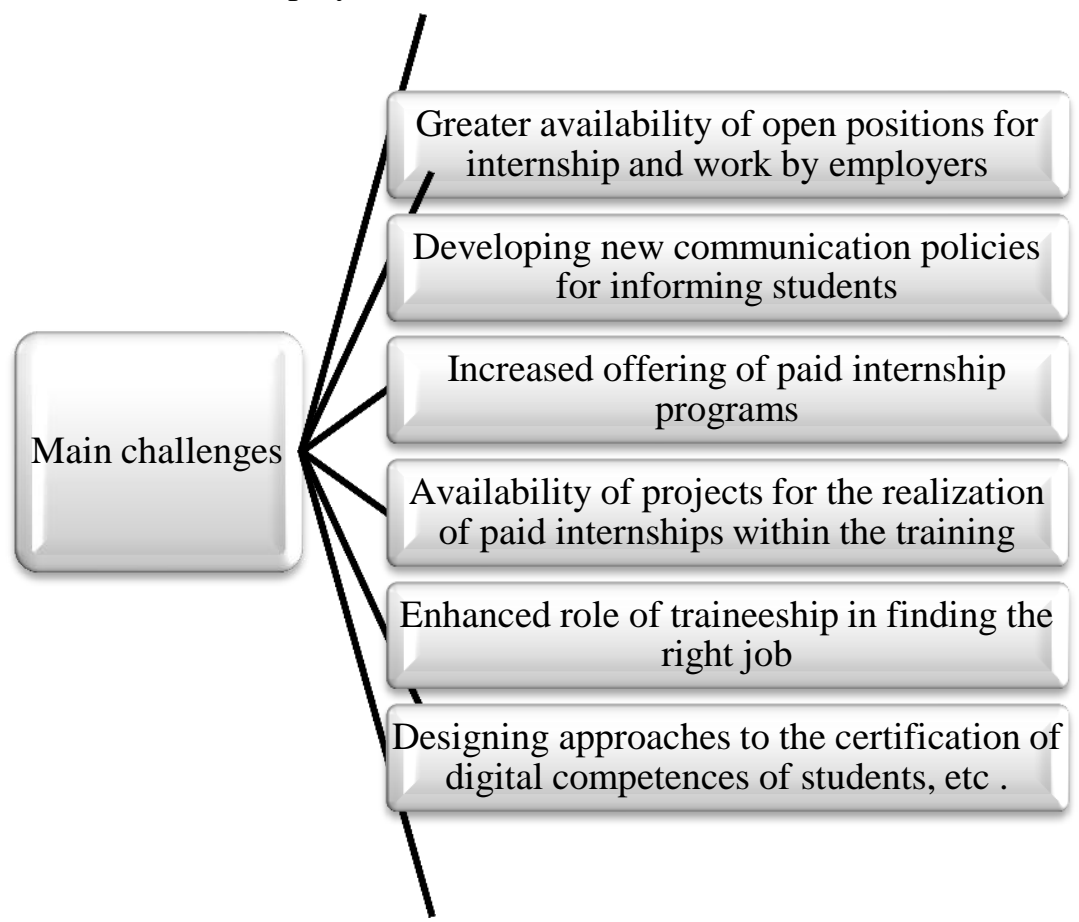

Figure 1. Main challenges

- Greater availability of open positions for internship and work by employers;

- Developing new communication policies for informing students;

- Increased offering of paid internship programs;

- Availability of projects for the realization of paid internships within the training;

- Enhanced role of traineeship in finding the right job;

- Designing approaches to the certification of digital competences of students, etc.

These challenges are the basis for looking for ways to expand the service offered by the career center.

\section{EXTENSION OF THE OFFERED SERVICES FOR STUDENTS}

The challenges faced by students' career development processes call for new approaches to modernize the career of career centers. This is happening against the backdrop of identified permanent changes in employers' demands and the labor market. In order to meet the main challenges, the ICCD at UNWE has made efforts in recent months in the following directions of expanding the services offered. This is done based on a careful analysis of the life cycle characteristics of career guidance (Figure 2):

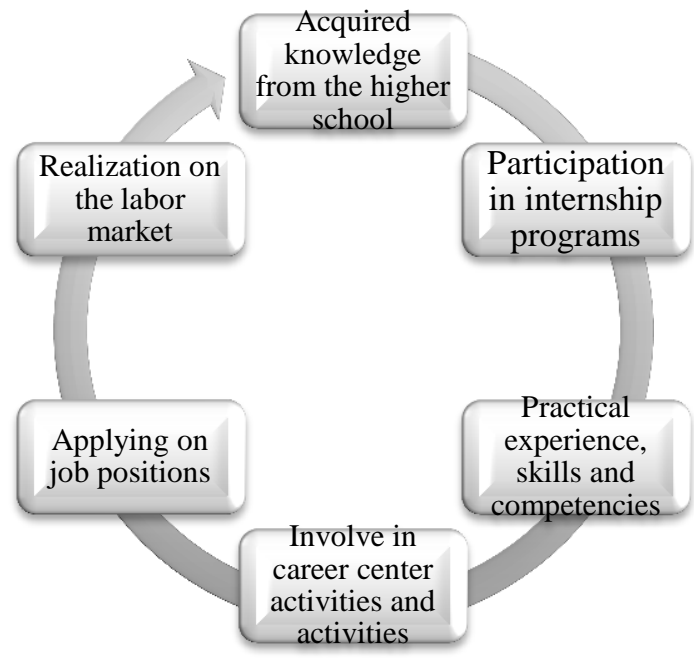

Figure 2 The role of career center services 
KIRILOV R.

The role of the career services offered by the career centers is growing. It has a direct link with the provision of opportunities for better realization of the students on the labor market. Along with this, one should also note the important place of practical training throughout the process. Acquiring work habits, adherence to work discipline, and dayto-day teamwork are important preconditions for easily finding a suitable job position. Considering these features from the middle of 2018, the ICCD has strengthened its work in expanding the services offered to students. This happens in the following directions:

- Developing a new communication strategy for informing students;

- Developing the functionality of the ICCD web site (Figure 3);
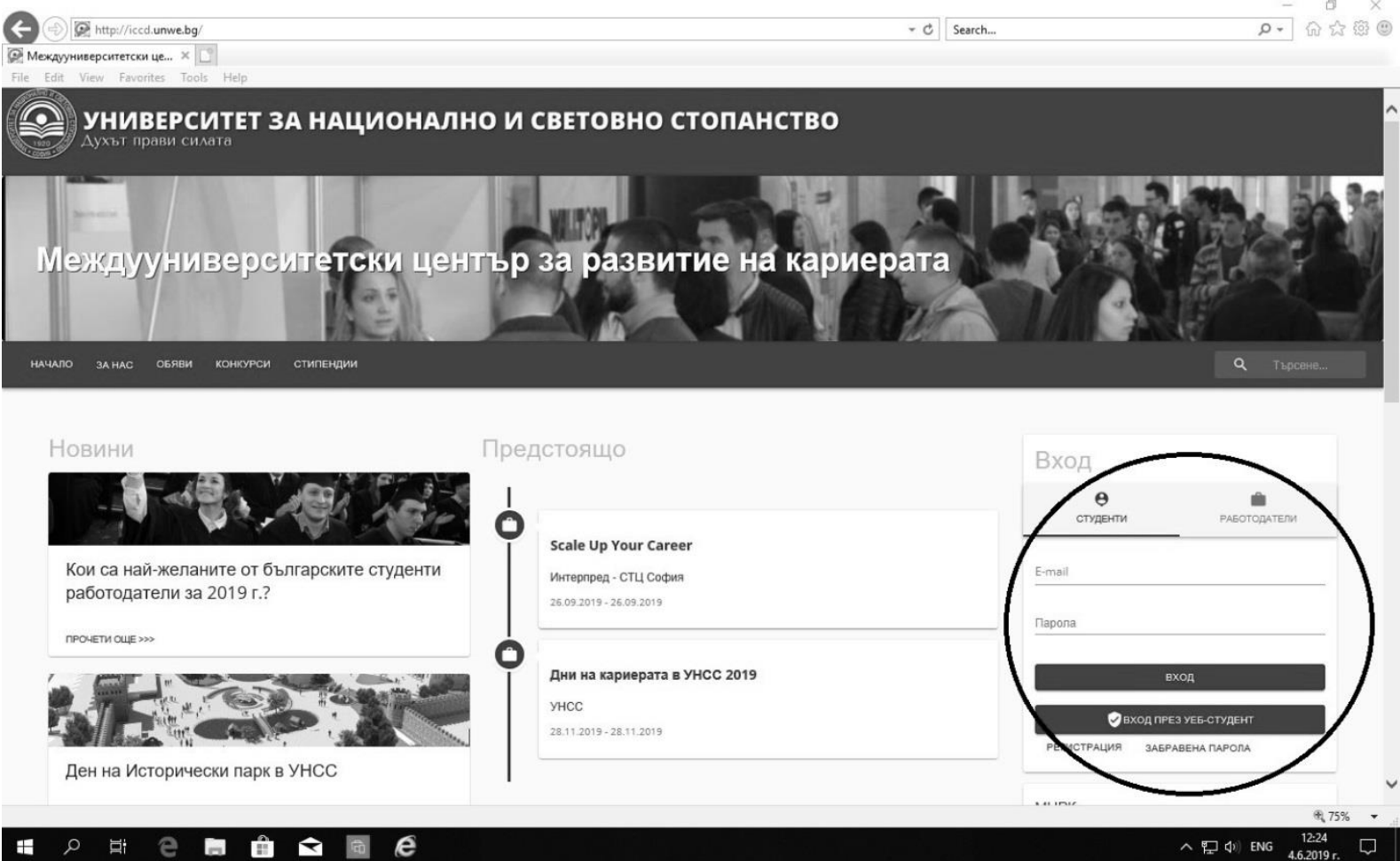

Figure 3. Website of the Interuniversity Center for Career Development [3]

- Entry capabilities for the ICCD system webbased for students through a single system input;

- Opportunities for applying for positions for internship and employment of CV employers;

- Opportunities for building an e-student portfolio;

- Looking for validation skills for students' digital competences;

- Offering opportunities for career counseling through social networks;

- Conducting periodic training on sales, communications, digital financial services, etc.;

- Expanding career forums and involving students in them;

- Inclusion of students in Olympiads and competitions for solving practical cases with employers;

- Offering advanced services in the field of traineeships and practical training, etc.

Enhanced web search capabilities are in line with some of the latest research in this area. In this study, we accept the definition given by Milev that internet monitoring is "monitoring of online information sources according to predefined criteria" [4]. In this sense, multiple filtering operations are needed daily [5]. This is an approach that is used to convert search capabilities to specific criteria into e-student portfolio data. For the realization of the new administrative services described above, a change was made in the organizational structure of the ICCD. Changes are in the following directions:

- Enhancing communication with student organizations;

- Co-organizing and participating in career forums;

- Joint organization of events with alumni clubs at UNWE;

- Use of career development information in software platform interoperability environments;

- A change in the duties of the employees of the separate structural units;

- Enhancing vertical communication with departments and faculties, etc.

Interoperability of systems is a very big challenge for public organizations. They increasingly focus on integrating systems and maintaining interoperability rules, especially when providing 
public e-services [6]. As regards the change in employee responsibilities, this process can also be perceived as the "new learning opportunity" described by Daskalova [7]. These changes provide opportunities for improving the work of the ICCD. This also happens based on expanded administrative services for students.

\section{CONCLUSIONS}

In conclusion, the following summaries should be made:

- The role of the career centers in higher education institutions will increase;

- More and more of the career services offered should be digitized. This will extend their use by the students and increase the efficiency of the processes;

- The development of e-student portfolio will provide additional benefits in finding a suitable job position;

- It is necessary to invest funds and efforts to develop the capacity of career centers to address the challenges of the labor market.

\section{REFERENCES}

1. Kirilova, K., Methodological Issues in Development of Public Electronic Services,
Economic and Social Alternatives, Issue 2, 2016, ISSN 1314-6556.

2. http://www.unwe.bg

3. http://iccd.unwe.bg/

4. Milev, P., Opportunities for Implementing Internet Monitoring in Public Organizations, Economic and Social Alternatives, Issue 2, 2018, ISSN 13146556.

5. Milev, P., Technological Issues of Implementing Software for Media Monitoring, Trakia Journal of Sciences, Vol. 11, Suppl. 1, pp 296-300, 2013, ISSN 1313-7069 (print), 1313-3551 (online).

6. Kirilova. K., Interoperability Issues in Bulgaria, Trakia Journal of Sciences, Vol. 13, Suppl. 1, 2015, pp. 103-106, ISSN 1313-7069 (print), 1313-3551 (online).

7. Daskalova, T., The human resources in the administration of "one-stop-shop", The Human Resources in the Panorama of Labor: a magazine for labor and social relations, Issue 2, 2009, pp. 26-35, ISSN 1312-305X. 